Preprint

UCRL-JC-137123

\title{
Effect of Vacuum on the Occurrence of UV-Induced Surface Photoluminescence, Transmission Loss, and Catastrophic Surface Damage
}

\author{
A. K. Burnham, M. Runkel, S. G. Demos, M. R. Kozlowski, \\ P. J. Wegner
}

This article was submitted to SPIE $45^{\text {th }}$ Annual Meeting, The International Society for Optical Engineering Symposium on Optical Science and Technology San Diego, CA

U.S. Department of Energy July 30 through August 4, 2000

Lawrence Livermore National Laboratory

July 20, 2000 


\section{DISCLAIMER}

This document was prepared as an account of work sponsored by an agency of the United States Government. Neither the United States Government nor the University of California nor any of their employees, makes any warranty, express or implied, or assumes any legal liability or responsibility for the accuracy, completeness, or usefulness of any information, apparatus, product, or process disclosed, or represents that its use would not infringe privately owned rights. Reference herein to any specific commercial product, process, or service by trade name, trademark, manufacturer, or otherwise, does not necessarily constitute or imply its endorsement, recommendation, or favoring by the United States Government or the University of California. The views and opinions of authors expressed herein do not necessarily state or reflect those of the United States Government or the University of California, and shall not be used for advertising or product endorsement purposes.

This is a preprint of a paper intended for publication in a journal or proceedings. Since changes may be made before publication, this preprint is made available with the understanding that it will not be cited or reproduced without the permission of the author.

This report has been reproduced directly from the best available copy.

Available electronically at http://www.doc.gov/bridge

Available for a processing fee to U.S. Department of Energy

And its contractors in paper from

U.S. Department of Energy

Office of Scientific and Technical Information

P.O. Box 62

Oak Ridge, TN 37831-0062

Telephone: (865) 576-8401

Facsimile: (865) 576-5728

E-mail: reports@adonis.osti.gov

Available for the sale to the public from

U.S. Department of Commerce

National Technical Information Service

5285 Port Royal Road

Springfield, VA 22161

Telephone: (800) 553-6847

Facsimile: (703) 605-6900

E-mail: orders@ntis.fedworld.gov

Online ordering: http:/ / www.ntis.gov/ordering.htm

\section{OR}

Lawrence Livermore National Laboratory

Technical Information Department's Digital Library

http: / / www.llnl.gov/tid/Library.html 


\title{
Effect of vacuum on the occurrence of UV-induced surface photoluminescence, transmission loss, and catastrophic surface damage
}

\author{
Alan K. Burnham*, Michael Runkel, Stavros G. Demos, Mark R. Kozlowski, Paul J. Wegner \\ Lawrence Livermore National Laboratory \\ Livermore, CA 94551
}

\begin{abstract}
Vacuum degrades the transmittance and catastrophic damage performance of fused-silica surfaces, both bare and silica-sol anti-reflective coated. These effects may be important in certain space application of photonics devices. When exposed to hundreds of 355-nm, 10-ns laser pulses with fluences in the 2-15 $\mathrm{J} / \mathrm{cm}^{2}$ range, transmittance loss is due to both increased reflectance and absorption at the surface. Spectroscopic measurements show that the absorbed light induces broadband fluorescence from the visible to infrared and that the peak photoluminescence wavelength depends cumulative fluence. The effect appears to be consistent with the formation of surface $\mathrm{SiO}_{\mathrm{x}}(\mathrm{x}<2)$ with progressively lower $\mathrm{x}$ as cumulative fluence increases. Conversely, low fluence CW UV irradiation of fluorescent sites in air reduces the fluorescence signal, which suggests a photochemical oxidation reaction back to $\mathrm{SiO}_{2}$. The occurrence of catastrophic damage (craters that grow on each subsequent pulse) also increases in a vacuum relative to air for both coated and uncoated samples. In both cases, the $50 \%$ damage probability for 100 one-mm sites decreases from about 45 to $35 \mathrm{~J} / \mathrm{cm}^{2}$ for superpolished fused silica at pressures in the $10^{-6}$ Torr range. The damage probability distribution in 10 Torr of air is close to that at one atmosphere of air. The damage morphology of the crater formed in vacuum differs substantially from that in air and has a more melted appearance and does not show cracking and flaking. These differences are possibly due to more coupling of the plasma shock wave into the surface with air present but slower heat dissipation in a vacuum. While it is attractive to propose that formation of sub-stoichiometric silica on the surface in a vacuum environment enhances the probability of catastrophic damage, initial experiments have not yet been able to establish a mechanistic link between the two phenomena.
\end{abstract}

Keywords: silica, transmittance loss, fluorescence, photoluminescence, vacuum, laser damage

\section{INTRODUCTION}

It is advantageous for some laser systems operate in vacuum. Space-based lasers are one obvious example. ${ }^{1}$ The motivation for our work was to understand the effect of vacuum on the UV optics of the National Ignition Facility (NIF). ${ }^{2}$ The problem of laser induced damage is prominent only on optical components exposed to the third harmonic of the fundamental laser wavelength. To minimize the risk of damaging the vacuum window between the majority of the laser and the target chamber, the UV conversion is performed after the vacuum window in a final optics assembly. The final optics assembly can most easily be held somewhere between the $10^{-4}$ Torr and 10 Torr due to other system design features.

In order to understand the lifetime of optics in the final optics assembly, we have been conducting extensive laser-induced damage experiments involving 1000 pulses of 351-nm light at average fluences of up to $12 \mathrm{~J} / \mathrm{cm}^{2}$ (7-10 ns) in both air and vacuum. During the course of this work, we noticed that optics exposed to these levels of integrated fluence in a vacuum tend to fluoresce when exposed to UV

\footnotetext{
${ }^{*}$ Correspondence: Email: burnham1 @1lnl.gov; Telephone: 925-422-7304; Fax: 925-422-1210
} 
light. Although this effect has been noticed once before ${ }^{3}$, there is extremely little published information on how vacuum affects the performance of lasers in the UV. Partial results from this study and similar experiments on $\mathrm{KH} 2 \mathrm{PO} 4$ have been reported earlier. ${ }^{4}$

\section{EXPERIMENTAL SECTION}

Samples used were 5-cm-diameter Corning 7980 substrates superpolished by Seso. Some were coated with colloidal silica (sol-gel) anti-reflective coatings with a 70-nm quarter-wave thickness chosen for maximum 350-nm performance. The sol-gel coatings were hardened by exposure to ammonia-water vapor fumes overnight. The optics were stored 1-2 months in new polyethylene teraphthalate glycol (PET-G) containers prior to use.

Laser damage experiments were performed on two laser systems. The first system is a LLNL-designed and built Q-switched, Nd-glass slab laser capable of producing $\sim 5 \mathrm{~J}$ pulses at $351 \mathrm{~nm}$ with $7 \mathrm{~ns}$ FWHM delivered as a rectangular flat-top beam. This system uses pickoff beams before and after the sample that are imaged on a CCD camera and a CCD-based microscope focused on the sample to detect laser damage in situ.

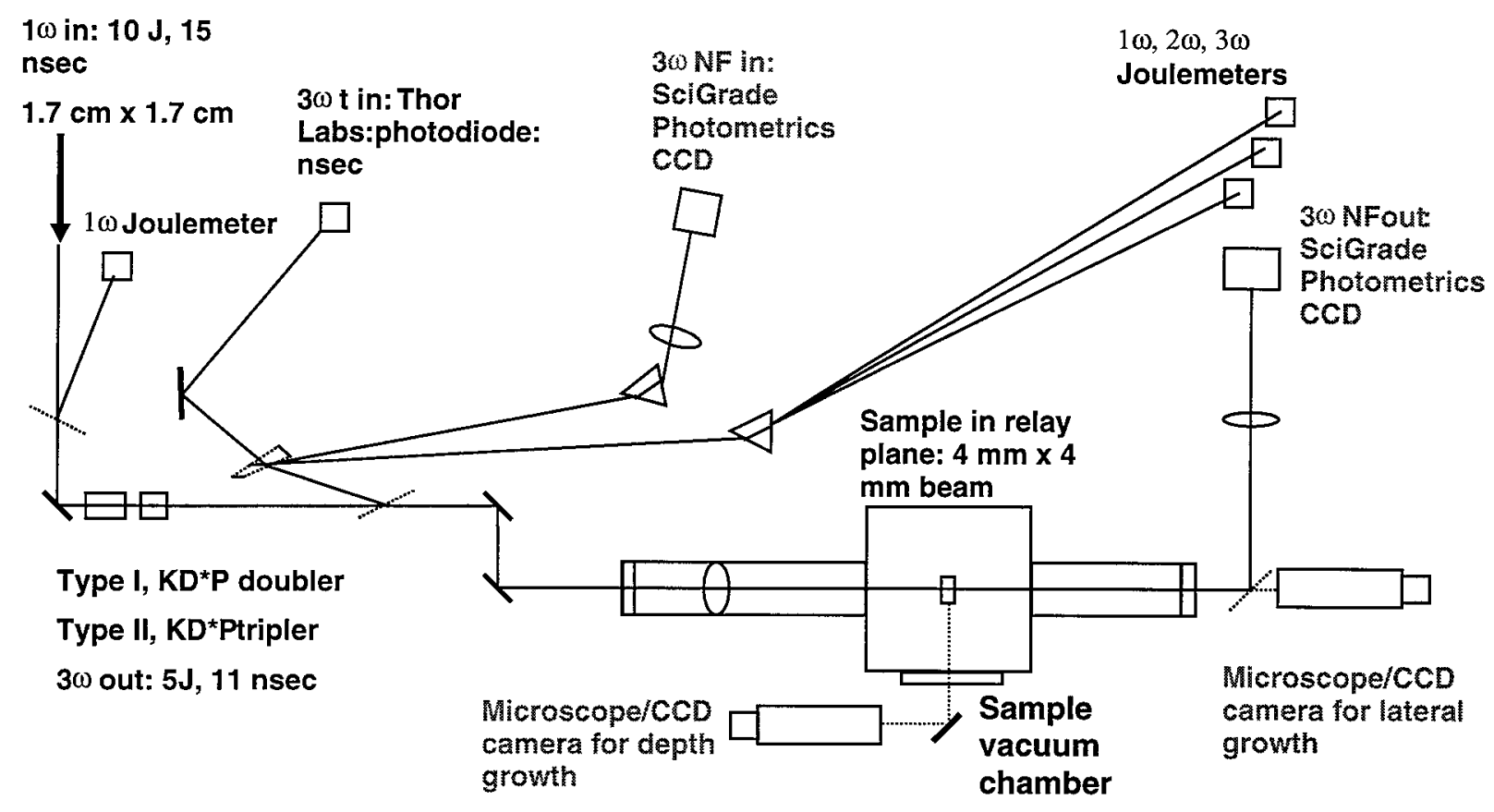

Figure 1. Schematic outline of the vacuum system and diagnostics used in conjunction with the Slab laser to test several mm square patches of optics.

The second system uses a table-top Spectra Physics GCR-350 Q-switched laser operating at $355 \mathrm{~nm}, 7.6$ $\mathrm{ns}$ (FWHM) at a repetition rate of $10 \mathrm{~Hz}$. The maximum output of the laser at $355 \mathrm{~nm}$ is $\sim 650 \mathrm{~mJ}$ in a near field diameter of $12 \mathrm{~mm}$. With these parameters, a telescope with 6-m effective focal length is needed to deliver a $0.5-1.0 \mathrm{~mm}$ (full width at $1 / \mathrm{e}^{2}$ of the peak fluence) Gaussian (in the far field) beam to the sample plane. A beam profile diagnostic system is used to measure fluence to an accuracy of $\pm 15 \%$. Damage is detected by a photomultiplier tube that measures changes in the light scattering signal from a HeNe laser that is colinear with the $3 \omega$-damage beam. A turbo pump backed by a mechanical roughing pump was used to provide vacuum to the $10^{-8}$ Torr range. This vacuum was attainable after several hours 
of pumping. The normal operating range was $\sim 10^{-6}$ Torr for damage tests. Damage tests were of two types: (1) a raster scan in which each illuminated area (near cylindrical volume in 3-D) receives a fixed fluence, and they overlap at the 50\% fluence level, and (2) a ramped damage test (called R/1) in which each of about 100 spots receives up to 100 pulses ramped from low to high fluence until damage occurs. The $R / 1$ test procedure consists of exposing a site to increasing fluence until the diagnostic detects damage. The fluence ramp for these tests was approximately $2 \mathrm{~J} / \mathrm{cm}^{2} / \mathrm{sec}$ or $0.2 \mathrm{~J} / \mathrm{cm}^{2} /$ pulse. Since each site damages, a large ensemble of data can be built up allowing a damage probability curve to be constructed - the probability of damage is plotted as a function of the test fluence.

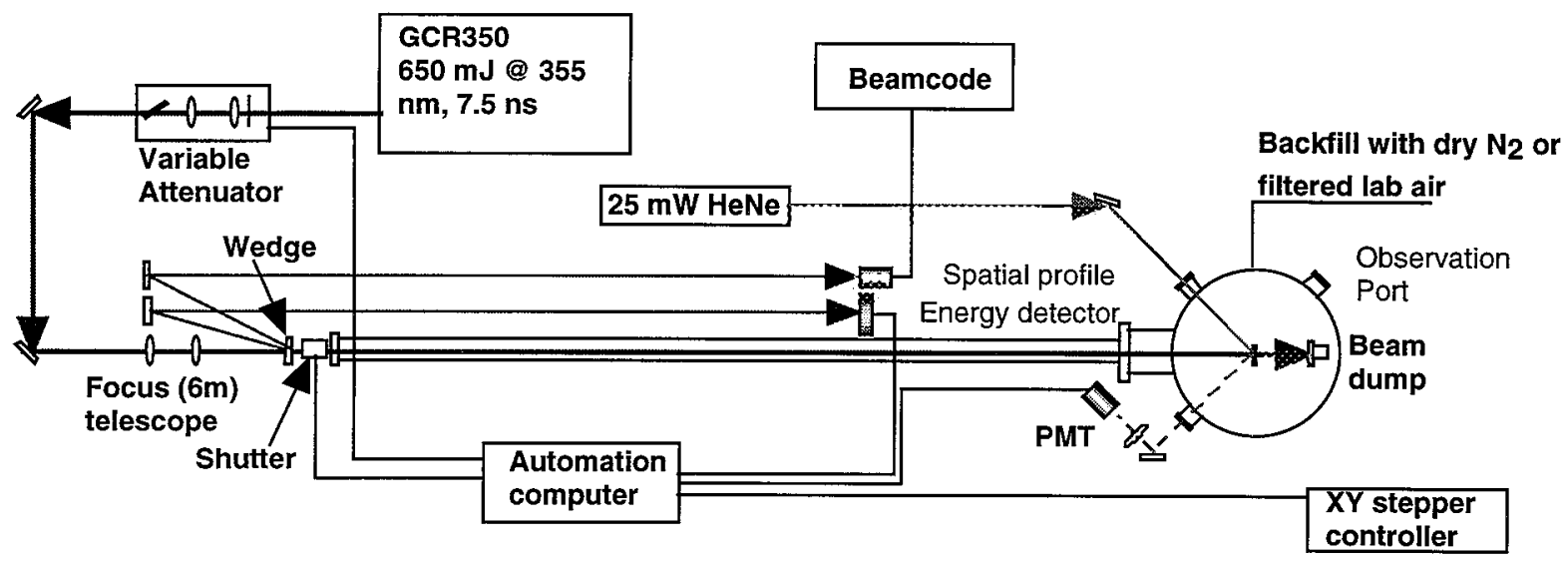

Figure 2. Schematic showing the top view of the air/vacuum damage system in the COLTS lab. It is essentially a duplicate of the original Zeus beamline adapted to accommodate the vacuum chamber.

Sample analysis was performed on two systems. The first system is utilized to study the samples using optical spectroscopy tools. The local PL spectra from the optic surface was measured using a $351 \mathrm{~nm}$ illumination from a CW Ar-ion laser as the excitation source and single pass spectrometer with a CCD array camera to measure the spectra at points along a slit passed through the spectrometer. The spatial resolution of the spectra is $\sim 5 \mu \mathrm{m}$. The experimental system is shown schematically in Figure 1 . The lens/pinhole combination provides confocal imaging capabilities with a vertical resolution of approximately $10 \mu \mathrm{m}$. This spectroscopic system is complemented by a microscopic fluorescence imaging system that is used to record images of the sample's surface with $1-\mu \mathrm{m}$ spatial resolution using its photoemission under 351-nm laser excitation. ${ }^{5}$ For these experiments, images were recorded using the visible $450-600 \mathrm{~nm}$ (Y-G) and the Near Infrared 850-1000 nm (IR) spectral regions of the emission which were selected using appropriate optical filters.

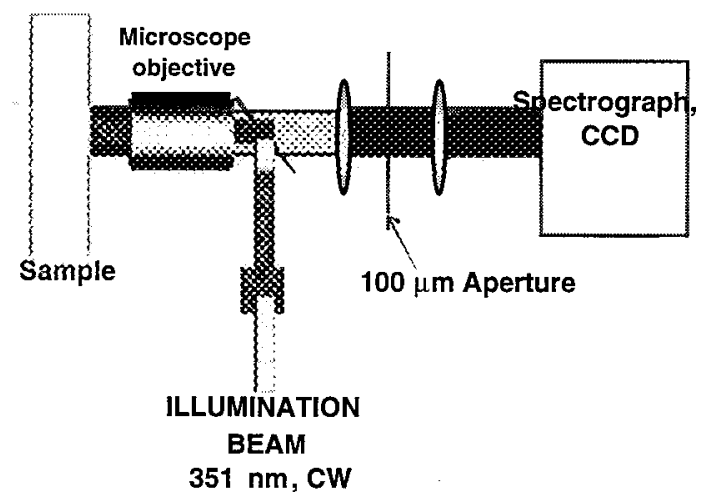

Figure 3. Schematic diagram depicting the confocal micro-spectroscopy system. 
The second is a LLNL designed and built photometer operating at 350-nm that is capable of measuring both transmittance and reflectance in a raster mode with a precision of about $0.1 \%$.

\section{UV-INDUCED ABSORBANCE, FLUORESCENCE, AND REFLECTANCE}

Fused silica optics receiving exposure to a significant amount of light in a vacuum lose transmittance as a function of integrated exposure and fluoresce from the surface upon exposure to UV light. Parts exposed to vacuum on one side and air on the other fluoresce only from the vacuum surface. Images formed using point by point mapping of the transmission and reflectance of the sample at $355 \mathrm{~nm}$ are given in Figure 4 for one of the exposed parts. Sites receiving the highest integrated fluence with the Slab Laser are quite visible in both reflectance and transmission. Changes from the baseline for the site receiving the largest exposure, 1000 pulses of $\sim 11 \mathrm{~J} / \mathrm{cm}^{2}$, on each optic are summarized in Table 1 . For solgel coated optics, baseline transmission is expected to be near $100 \%$; for bare sample the expected value is $~ 92 \%$ due to a $4 \%$ Fresnel loss at each surface. The unexposed bare sample 1 reflectance data is very close to the theoretical value of $4.4 \%$ for the S-polarization at $20^{\circ}$ incidence measurement conditions, but there appears to be a $40 \%$ calibration error in the reflectance measurements for bare sample 2 . Reducing the reflectance change upon exposure by $1.4 \mathrm{x}$ reduces it to $0.12 \%$, which is close to the value of $0.11 \%$ for BS03.

Table 1. Summary of approximate changes in transmission and front-surface reflectance for optics exposed to 1000 pulses of $351-\mathrm{nm}$ light at about $11 \mathrm{~J} / \mathrm{cm}^{2} /$ pulse.

\begin{tabular}{ccc} 
Optic & Max $\Delta$ Transmission & Max $\Delta$ Reflectance \\
\hline Bare sample 1 (BS03) & $92.0-93.0=1.0 \%$ & $4.49-4.38=0.11 \%$ \\
Bare sample 2 (BS04) & $92.5-91.2=0.7 \%$ & $6.25-6.08=0.17 \%$ \\
sol AR coated sample 1 (Sol15) & $99.4-98.4=1.0 \%$ & $1.1-0.5=0.6 \%$ \\
sol AR coated sample 2 (Sol16) & $100.0-99.0=1.0 \%$ & $1.1-0.5=0.6 \%$
\end{tabular}

The spectral characteristics and the intensity of the emission from the irradiated (in vacuum) area on the surface of the sample change depending on the number and fluence of the 355-nm laser pulses. Emission spectra under 351-nm CW photoexcitation are shown in Figure 5. Parts of the sample exposed to a smaller number of 355-nm pulses or to lower fluences (at the edges of the 355-nm laser beam) exhibit a broadband emission with maximum intensity at $\approx 580 \mathrm{~nm}$. The spectrum is shifting at longer wavelengths for additional exposure to 355-nm pulses. Experimental results suggest that for the bare samples, the peak of the emission under extensive exposure to $355-\mathrm{nm}$ pulses shifts in the NIR spectral region. For the coated sample, the emission spectrum shifts to a lesser degree with the emission peak centered at $\approx 700$ nm.

Figure 6 shows the digitized intensity of microscopic fluorescence images from parts of the same sample that were exposed to different 355-nm laser fluences and number of pulses for (a) uncoated and (b) coated samples. The experiments were performed using two set of optical filters allowing for imaging using the emission from the sample under $351 \mathrm{~nm}$ CW excitation in the $450-600 \mathrm{~nm}$ (Y-G) and 850-1000 $\mathrm{nm}$ (IR) spectral regions. This figure demonstrates the shifting of the spectrum from visible to far-red and NIR as well as the change of the emission intensity for the coated and uncoated samples.

The mechanistic reason for the change in transmittance appears to be the formation of a layer of $\mathrm{SiO}_{x}$ on the surface of the optic. Our fluorescence spectra are similar to those reported in the literature for these materials. ${ }^{6}$ Increased exposure results in a shift of the peak fluorescence from the visible to infrared, 
which is normally interpreted as a decrease in the oxygen:silicon ratio. To test this model, fluorescent sites in samples that were exposed to $355-\mathrm{nm}$ laser pulses in vacuum were subsequently exposed to low fluence CW UV-laser irradiation in air. This exposure caused changes in the emission characteristics, with the spectrum originally shifting towards shorter wavelengths followed by a reduction in intensity, which suggests a photochemical oxidation reaction back to $\mathrm{SiO}_{2}$.

The experimental results summarized in Table 1 indicate that there is a notable difference between coated and uncoated parts. Doubling the single-side reflectance loss for the coated parts accounts for essentially all the transmittance loss, while the corresponding calculation for the bare parts suggests that most of the change is due to a change in absorbance. Since the amount of fluorescence from both coated and uncoated parts is similar (see Figure 6), the cause for this difference is not obvious. It is possible that the type of absorbing material (namely the value of $\mathrm{x}$ in $\mathrm{SiO}_{\mathrm{x}}$ ) formed on the surface in the coated and the uncoated samples is different leading to different absorption coefficients at $355 \mathrm{~nm}$. ${ }^{7}$ This model is supported by the measured emission spectra shown in Figure 5 where (as indicated above) the emission spectrum of the bare samples is shifted further into the NIR spectra region than the coated samples.
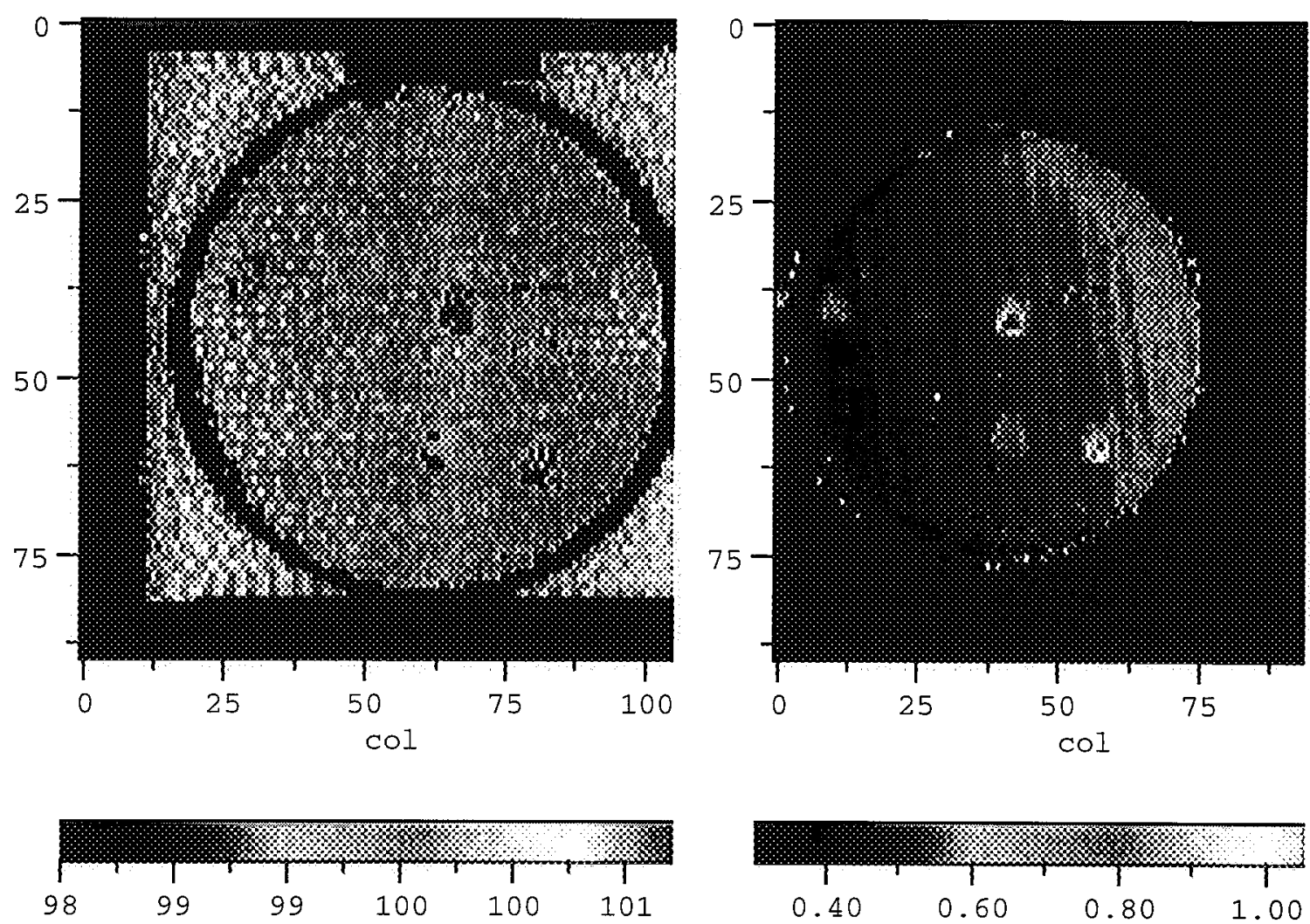

Figure 4. $3 \omega$ transmittance and reflectance maps of sol-gel coated silica sample 2 (Sol16). Four irradiation spots are clearly visible in the transmittance image, and an additional faint spot is visible in reflectance. The horizontal line in the upper right is caused by mishandling. 


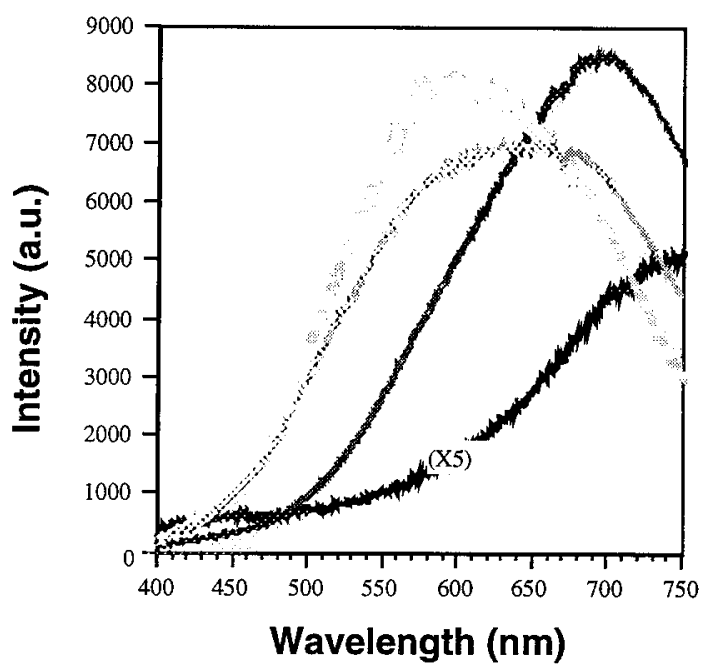

Figure 5. Emission spectra under 351-nm photoexcitation of Slab-Lab irradiated areas on coated and bare fused silica parts.
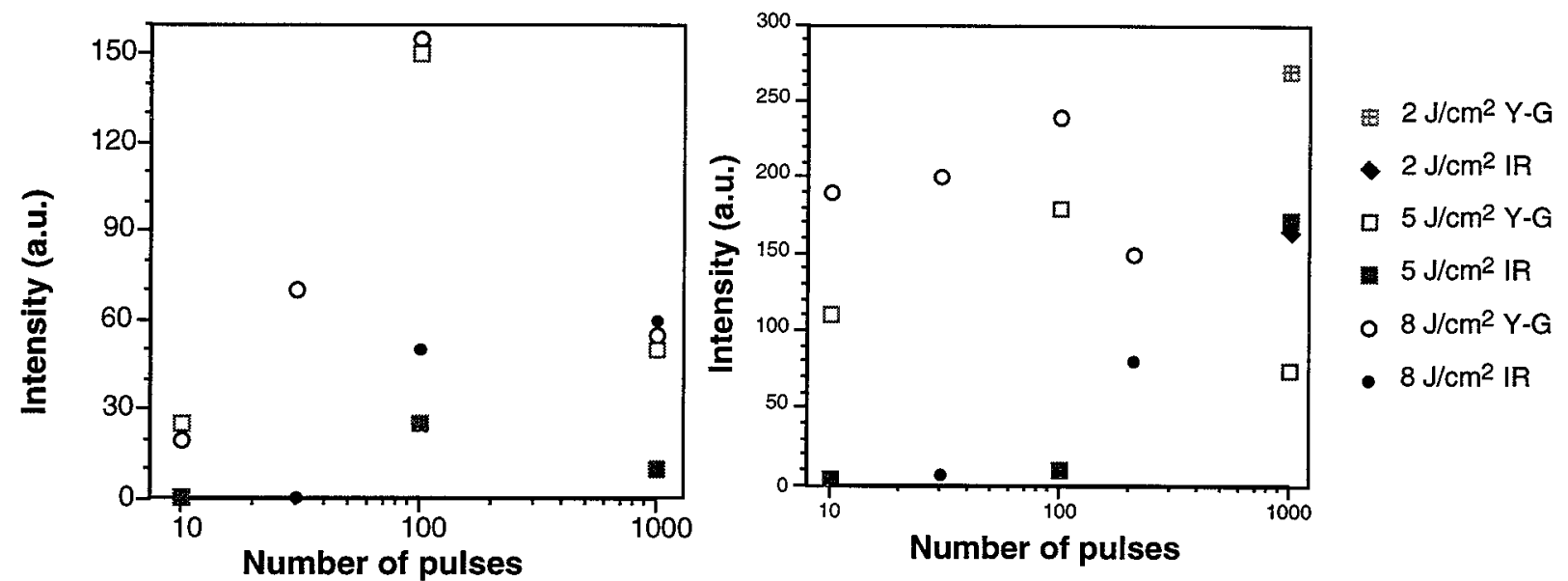

Figure 6. Digitized intensity of microscopic fluorescence images of samples using the 450-600 nm (Y-G) and 850-1000 nm (IR) spectral region as a function of laser fluence and number of pulses for (a) uncoated parts and (b) coated parts.

\section{EFFECT OF VACUUM ON LASER-INDUCED DAMAGE}

Laser damage requires some energy absorption mechanism, although field enhancement and mechanical defects may contribute to damage susceptibility. Consequently, we proposed that the formation of a thin absorbing layer due to $\mathrm{SiO}_{\mathrm{x}}$ formation may increase the occurrence of laser-induced surface damage. We then measured the difference in damage performance between air and vacuum for both bare and coated substrates using ramped fluence (R/1) tests. The results of these tests are given in Figure 7 . There is about a $10 \mathrm{~J} / \mathrm{cm}^{2}$ decrease in the damage probability curve for tests in vacuum. The possibility that vacuum related or sequence-dependent contamination might contribute to the difference was discounted by both reversing the order of the tests and by x-ray fluorescence analysis of the samples after testing. Additional experiments were done in which the spots were pre-irradiated with 400 pulses at $5 \mathrm{~J} / \mathrm{cm}^{2}$. These damage probability curves overlay the corresponding ones in air and vacuum, but it is possible that errors in repositioning due to stage backlash prevented a true test of pre-irradiation. Samples coated with a sol-gel antireflective layer were tested similarly. Results in Figure 8 show virtually identical behavior as for the bare samples. 

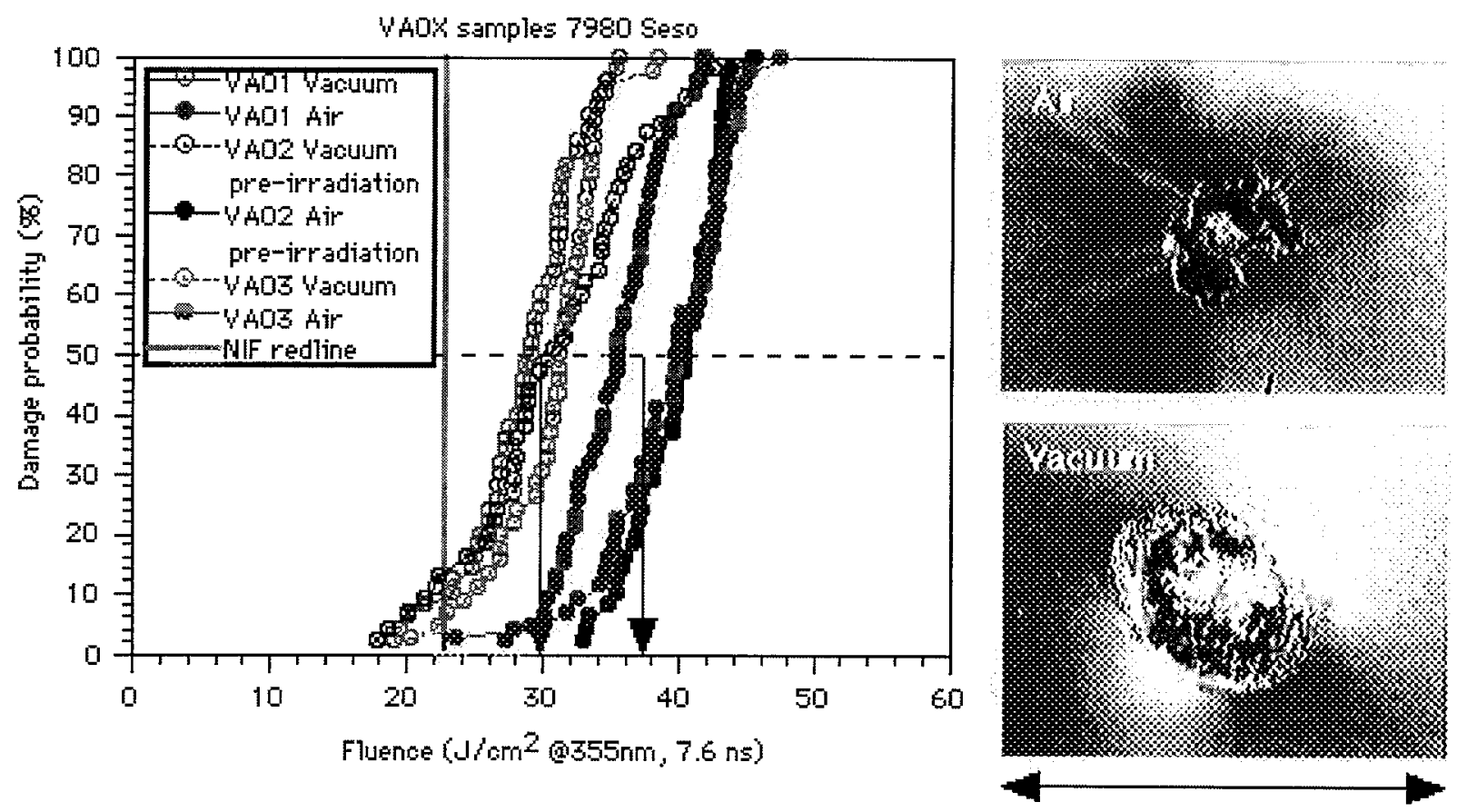

$1.13 \mathrm{~mm}$

Figure 7. Compilation of R/1 test data on bare surfaces in air and vacuum, with and without pre-irradiation. The average performance drop between air and vacuum is $26 \%$ based on $50 \%$ damage probability. Also shown are the different damage crater morphologies produced in air and vacuum. For clarity, the fluence error bars of $\pm 15 \%$ are not shown on the damage data. The sites in air usually have a scalded area around the crater and more cracks. The centers of both craters have molten regions.

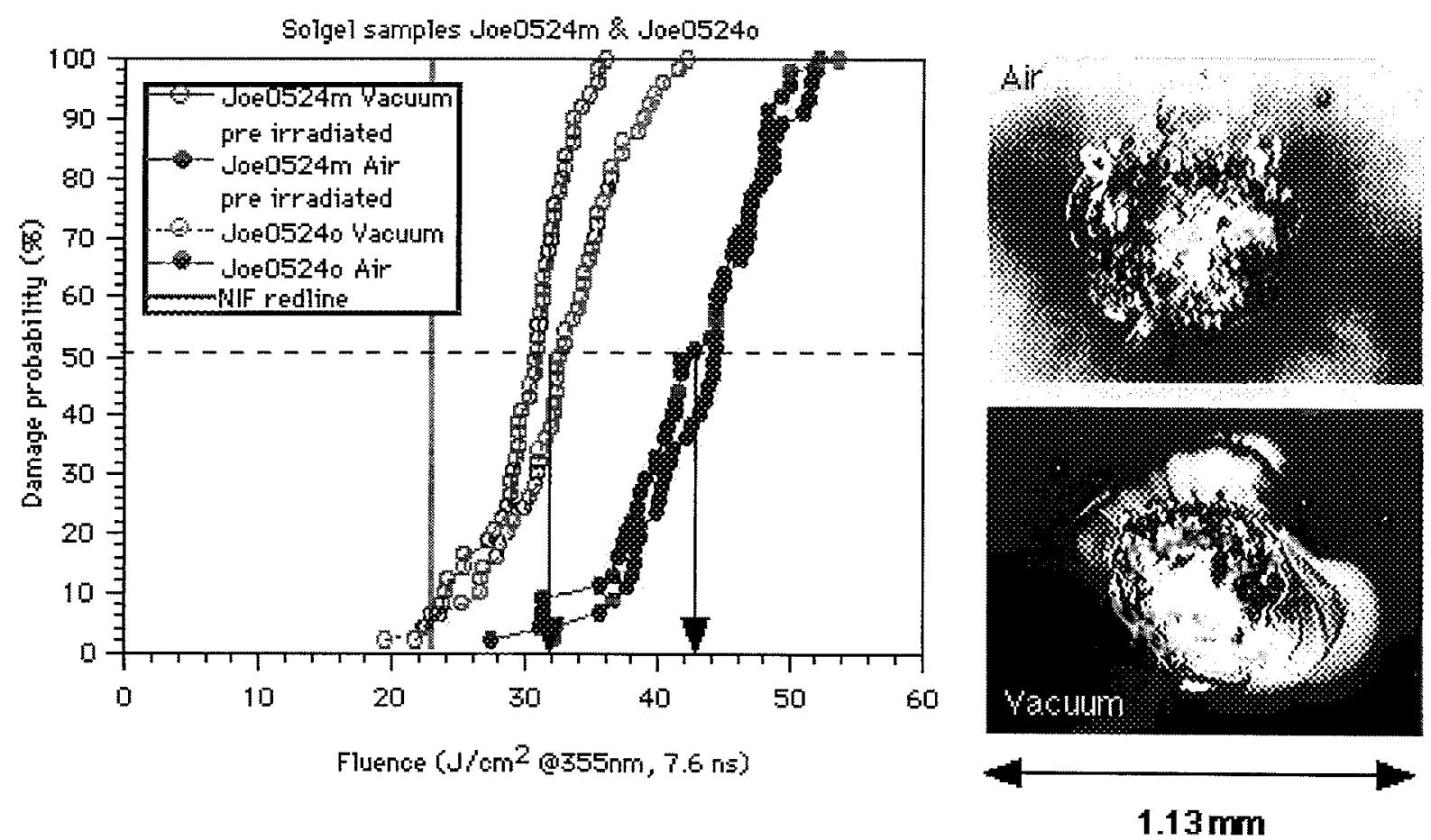

Figure 8. Results of damage testing on solgel coated samples. The fluence drop between air and vacuum is $34 \%$. Damage morphologies in air are very similar to the bare substrate case. The coating around the pit is discolored, indicating a compositional or thickness change, but has not been peeled from the substrate. 
The possibility that pre-irradiation might increase damage probability was also tested by raster scanning two bare silica optics at fixed fluence of $20 \mathrm{~J} / \mathrm{cm}^{2}$. Each optic had two $3 \times 3-\mathrm{mm}$ areas pre-exposed to 1000 pulses of the Slab laser at $4 \mathrm{~J} / \mathrm{cm}^{2}$. The raster step was chosen to be $0.5 \mathrm{~mm}$, which when compared to the $0.8-\mathrm{mm}$ damage beam indicates a thorough sampling of the rastered area. Although there was a notable increase in damage initiation in vacuum relative to air at $20 \mathrm{~J} / \mathrm{cm}^{2}$, there was no apparent difference in damage initiation in the pre-irradiated sites relative to the virgin optic in either the air or vacuum case. Consequently, we cannot prove a mechanistic link between the lower damage resistance in a vacuum and enhanced absorption due to $\mathrm{UV}$-induced $\mathrm{SiO}_{\mathrm{x}}$ formation.
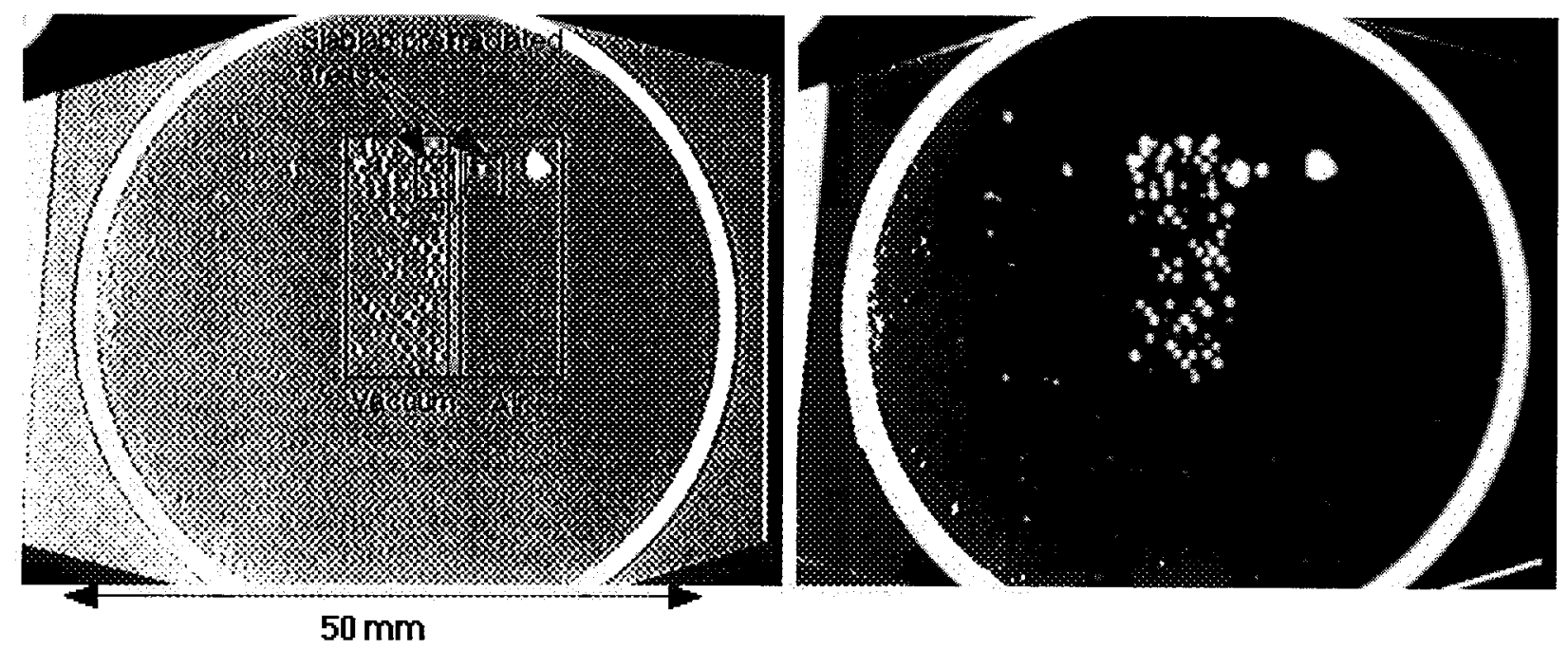

Figure 9. Results of a step raster scan test on bare fused silica. The air-tested area survived exposure to $20 \mathrm{~J} / \mathrm{cm}^{2}$ without damage. The large sites are due to exposure at $30 \mathrm{~J} / \mathrm{cm}^{2}$.

Stephen et al. ${ }^{3}$ report a similar decrease in transmission and increase in luminescence in a vacuum, and they also report that low pressures of gas mitigate the effect. Consequently, we tested whether a partial pressure of 10 Torr of (filtered) air in the chamber could would have a significant mitigation effect. This pressure can be a feasible solution for NIF with the planned 1-cm-thick debris shield separating the target chamber from the final optical assembly. The 10-Torr damage probability curve is virtually identical to that in one atmosphere of air. 

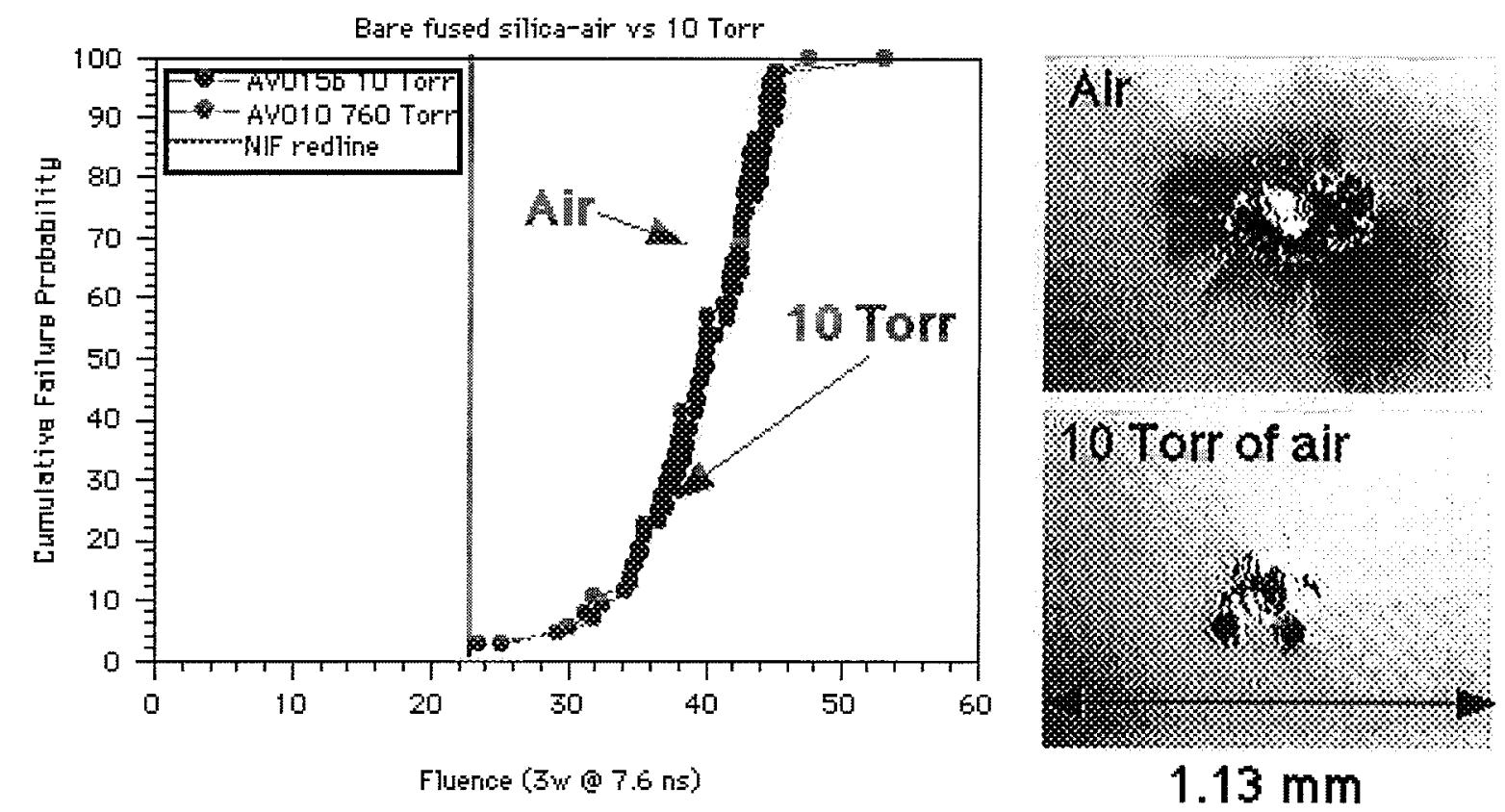

Figure 10. Results of testing in 10 Torr of atmospheric gas mix. There is no difference between the air and 10-Torr probability curves. The damage morphology at 10 Torr is intermediate between the morphology in air and vacuum but closer to that in vacuum.

\section{DISCUSSION}

Vacuum has two distinct deleterious effects on optics: (1) reduction of transmittance due to formation of an absorbing surface layer of $\mathrm{SiO}_{\mathrm{x}}$, and (2) reduction of the high-fluence damage initiation probability. The two effects may be related, although we were not able to demonstrate the link through pre-exposure experiments.

The transmittance loss appears to be caused by a combination of both reflectance and absorbance, although absorbance seems to be relatively more important for samples coated with a sol-gel antireflective coating. Taking into consideration the energy required to release an oxygen atom from $\mathrm{SiO}_{2}$, it appears unlikely that UV light could directly liberate oxygen from the pure silica surface. Maybe absorbed organic material is involved and acts as a reducing agent, thereby liberating carbon monoxide. Perhaps this is related to the organic-contamination laser damage observed by Hovis et al. ${ }^{8}$ Consequently, the well-known propensity of sol-gel coatings to absorb organic contamination may enhance the effect. Simultaneous exposure to UV-light and oxygen easily reverses the effect. This reversal is probably related to the longer optics lifetimes and transmission recovery observed by Chow et al. ${ }^{10}$ for dichroic coatings in high average power laser vacuum resonator using pressures above 10 Torr. Similarly, relatively low pressures of oxygen (10 Torr) appear to eliminate the enhanced high-fluence damage that occurs in a vacuum. Since we have no demonstrated mechanism for the increase in damage crater initiation in a vacuum, it is difficult to extrapolate to other conditions.

\section{ACKNOWLEDGMENTS}

We appreciate the contributions of numerous other laser damage team members, particularly Mary Norton, Mike Staggs, and Lori Zeller. This work was supported under the auspices of the U.S. Department of Energy by the University of California Lawrence Livermore National Laboratory under contract No. W-7405-ENG-48. 


\section{REFERENCES}

1. E. W. Taylor, M. Osinski, M. Watson, T. Svimonishvili, S. D. Pearson, and J. Zetts, "Overview of photonic materials and components for application in space environments," SPIE Vol. 3872, pp. 72 83, 1999.

2. J. R. Murray, "Overview of the National Ignition Facility," in NIF Laser System Performance Ratings, Supplement to SPIE Volume 3492, pp. 1-10, 1998.

3. T. M. Stephen, B. Van Zyl, R. C. Amme, "Degradation of vacuum-exposed $\mathrm{SiO}_{2}$ laser windows," SPIE Vol. 1848, pp. 106-110 (1992).

4. S. G. Demos, A. Burnham, P. Wegner, et al., "Surface defect generation in optical materials under high fluence laser irradiation in vacuum," Electron. Lett. 36, pp. 566-567, 2000.

5. S. G. Demos, M. Staggs, M. Yan, H. B. Radousky and J. J. De Yoreo "Microscopic fluorescence imaging of bulk defect clusters in KH2PO4 crystals," Optics Letters, 24, 268, 1999.

6. R. Carius, R. Fischer, E. Holzenkampfer, and J. Stuke, "Photoluminescence in the amorphous system $\mathrm{SiO}_{x}, " J$. Appl. Phys. 52, pp. 4241-4243, 1981.

7. H. R. Philipp, "Optical properties of non-crystalline $\mathrm{Si}, \mathrm{SiO}, \mathrm{SiO}_{\mathrm{x}}$ and $\mathrm{SiO}_{2}$," J. Phys. Chem. Solids, 32, 1953-1945, 1971

8. F. E. Hovis, B. A. Shepherd, C. T. Radcliffe, A. L. Bailey, and W. T. Boswell, "Optical damage at the part per million level: the role of trace contamination in laser induced optical damage," SPIE vol. 2114, pp. 145-153, 1993.

9. R. Chow, L. V. Berzins, P. A. Arnold, G. V. Erbert, "Reversible laser damage of dichroic coatings in a high average power laser vacuum resonator," SPIE Vol. 3902, pp. 283-291 (2000). 